\title{
The Influence Of Construction Materials On Sustainable Constructions: A Study In Wolaita Zone, Southern Ethiopia
}

\author{
AshebirAlyew Mamo ${ }^{1}$, AshenafiReta Tessema ${ }^{2}$ \\ ${ }^{1}$ Assistant Professor, Department of Civil Engineering, WolaitaSodo University, WolaitaSodo, Ethiopia \\ Email id: ashebiralyew@gmail.com \\ ${ }^{2}$ Assistant Professor, Department of Civil Engineering, WolaitaSodo University, WolaitaSodo, Ethiopia \\ Email id: hiashe@gmail.com
}

\begin{abstract}
Studies on sustainable construction materials are on the increase with their Social, Environmental and Economic benefits. The research categorizes the key factors for sustainable construction materials. The method used for the study was that of a survey which depends on a questionnaire with five scale of measurements of Likert scale (1 for "Strongly Insignificant" (SI), 2 for "Insignificant" (IS), 3 for "Neutral" (N), 4 for "Significant" (S) and 5 for "Strongly Significant" (SS)) to create data for the analysis. For the purpose of this study, 18 indicators from the different dimensions summarized from the literature were presented to the respondents in the form of questionnaire, and replies were collected and analyzed using Likert scale on Microsoft Excel. The research result identified 18 underlined keyfactor for sustainable construction materials. Such as, Escalation of material prices, Material and equipment cost, Labor cost, Cost of variation orders, Waste rate of materials, Conformance to specification, Availability of personals with high experience and qualification, Quality of equipment and raw materials, Wastes around the site, Climate condition in the site, Human toxicity, Empowerment \& participation, Adaptability, Social value, Life span, Initial cost, Job creation, and Tourism.Commonlythe study recommends that emphasis should be given for the identified key factors especially on the top five ranked key factors for Sustainable Construction Materials.
\end{abstract}

Key words: sustainable construction,sustainable constructions, environment, climate, quality, cost

\subsection{Background of the Study}

\section{INTRODUCTION}

Sustainability is portion of recent life and is a main element to just about every industry. It's important to consider the impact of everyone's actions on the planet, individually and as a collective. But what does it mean to be 'ecofriendly', and what portion does sustainability play when using construction materials nowadays. Sustainable buildings constructions are structures that are built in an environmentally responsible manner by exploitingthe use of materials, lesseningthe use of resources and ensuring the health and well-being of residents and the surrounding constructed environment both currently and for generations to come. Sustainable building requires that of the construction participants with the environment focusing on renewable energy, sustainable materials, water conservation, site development and indoor environmental quality. The benefits of sustainable construction can be generally categorized in to ecological, financial and societal benefits.

\subsection{Statement of the Problem}

Sustainable construction materials principle used the following elements like building construction to last a lifetime, advanced framing techniques, conserve energy and save money, have a healthy, comfortable sustainable home, minimize waste through sustainability, buy local products, building with wood, make the world a better place, improved resale value, many styles in sustainability.

Based on the fundamental objective of this research work, the potential impacts of changing structural materials to sustainable construction are related to construction engineering demands, needs and drivers and to the acceptance of sustainability concepts considering the activities in the construction industry where it called upon to make a difference in the process to identify aspects of sustainable construction that can realistically be addressed and areas where action can make a significant contribution to achieving sustainability in selecting environmentally preferable building materials in the achievement to increase the goal of sustainability issues in the construction projects.

The previous research studies addressed the problems with materials selection. Though, most of these studies have failed to properly and adequately establish the definition for 'sustainable construction materials'. Here to fore, there 
is no universally accepted definition for 'sustainable building materials' [1]. This makes it very difficult to establish principles and guidelines that enable sustainable building materials to align with the principles and goals of sustainable development of the construction industry in the city.

Thus, the problem statement is developed as in considering that the construction industry is as one of the most resource consumers and has been described as the most of the biggest users of resources in the area. Furthermore, the aim of the study is identify the influence of construction materials on sustainable construction in Wolaita Zone. The study is relevant to various stakeholders but the primary focus is for the city municipalities, researchers, property developers, construction contractors and building manufacturers.

\subsection{Objectives of the Study}

The central goal of this research work is to identify the Influence of Construction Materials on Sustainable Construction in Wolaita Zone as part of Southern Ethiopia. The research study specifically focuses on sustainable construction materials on building construction projects.

\subsection{Definitions and Concepts}

\section{REVIEW OF LITERATURES}

To support the joint operation or action in the sustainable building and construction sector, consensus based definitions are needed with regard to what this sector consists of, who the principal stakeholders are and to identify the range of measures that could be adopted, with the overall aim of achieving sustainability.

Concrete: a building material created by a hardened mixture of cement, gravel, sand, and water. It is used for slabs, columns, and other types of structures.

Construction materials: the engineering structures are composed of the engineering materials or building materials or materials of construction. It is necessary for the civil engineer to become conversant with the properties of such materials.

Mortar: In masonry, mortar is the paste that is used to bind stones, bricks, and other similar types of units used to construct the walls of a building. Mortar can be made up of a variety of things, such as asphalt, pitch, or clay.

Sustainable construction: according to [2]"sustainability offers a way of interacting with our world which reconciles the ubiquitous human desire for a high quality of life with the realities of our global context. It calls for unique solutions for improving our welfare that do not come at the cost of degrading the environment or impinging on the wellbeing of other people". They have singled out social, economic, biophysical and technical attributes of sustainability to advance understanding of the concept of sustainable construction.

\subsection{Building Materials}

Building materials largely determine the buildings' energy consumption and environmental impacts, and have a significance impact on the sustainability of buildings [2].

Furthermore, building materials have an important role to play in building sustainability, and they also engage in the development of the economy. The application of building/or construction materials impacts by several methods primarily because of the heavy use of nonrenewable energy and the quantity of dissipation and contaminants produced by the material life cycle [3]. In fact, stakeholders of the construction began while comprehending the importance of managing the environmental effects necessitated from the construction sector. Choosing building materials needs to be strengthened to take into account the sustainability properties of materials and considerations such as cost, availability, and appearance have been better chosen [4]. Sustainable construction resources are mainly compliant with the limits of nonrenewable assets, operate according to life cycles, and environment interactions, are nontoxic, is energy-friendly and water-efficient, made of recycled materials, and can also be recycled by themselves [5]. Therefore, the importance of construction materials in the delivery of sustainable building cannot be underestimated. 


\subsection{Selection of Sustainable Building Materials}

Careful selection of environmentally sustainable building materials is the easiest way for architects to begin incorporating sustainable design principles in buildings. Traditionally, price has been the foremost consideration when comparing similar materials or materials designated for the same function. The building and construction industry consumes great quantities of raw materials and energy. According to[6] approximately $24 \%$ of global raw materials were consumed by the industry. Traditional building materials including steel, concrete, aluminum and glass are high energy content materials. Buildings impact on the environment during their whole life cycle and the choice of materials used will impact on their overall performance. They are used in various stages, from initial construction through to the operation stage when the buildings are maintained and refurbished to preserve their normal functioning until the end of their service life. Therefore, it is an area that designers can have significant inputs if they are properly informed in the area of incorporating sustainable building materials into the design of the building.

According to [1] the selection of building materials plays an important role in achieving the goal of sustainable development in the construction industry. Choosing materials with high contents of embodied energy entails an initial high level of energy consumption in the production process, which associated with high levels of GHG emissions [6].

\subsubsection{Sustainable Building Materials Properties}

Many properties differentiate sustainable building materials according to the life cycle of materials. If one or more of the following characteristics apply, materials may be called sustainable [7]. Improving indoor air quality through the elimination of Volatile Organic Compounds (VOC) pollution.

- Recycled contents generated in whole or in part out of post-industrial or post-consumer waste.

- Low maintenance conditions and performance.

- They are made from renewables.

- The energy needed for the manufacturing and transporting of materials is minimal.

- Ozone destruction free.

- There is less toxicity.

- They are materials from the local region.

- They are capable of being reused.

- They have capable of being recycled.

- They are biologically degradable.

- Through production or construction cycles, waste generation decreased.

- They are energy-friendly and they help minimize operating energy when occupying the building.

- They help to save water.

\subsection{Construction Materials Conservation}

In particular, large amount of minerals resources are consumed in the built environment and most of these mineral resources are non-renewable. Therefore, it is important to reduce the use of non-renewable materials. According to [8] this should be incorporated for consideration at the project initiative and design phases, where the selection of materials is very important and the choice should be based on the materials' environmental impacts. At the construction and deconstruction phases, various methods can also be used for reducing the impacts of materials consumption on the natural environment.

\subsection{Sustainable Implementation of Construction Materials}

The construction process of any building or structure involves the implementation of many materials which typically differ from each other. [4] Suggestion in order to arrive at a sustainable future in the building industry, adoption of multi-disciplinary approach consisting of a number of features such as: energy saving, improved use of materials, material waste minimization, pollution and emissions control etc. There are many ways in which the current nature of building activity can be controlled and improved to make it less environmentally harmful, without reducing the 
useful output of building activities. To create a competitive advantage using environment-friendly construction practices, the entire life-cycle of buildings should, therefore, be the context under which these practices are carried out. A review of different literatures has identified three general objectives which should shape the framework for implementing sustainable buildings and construction, while keeping in mind the principles of sustainability issues (social, environmental and economic) identified previously. These objectives are:

1. Resource conservation

2. Cost efficiency and

3. Design for Human adaptation

\section{RESEARCH METHODOLOGY}

\subsection{Research Design}

The design used for this study is that of a survey which relied on a questionnaire surveys to generate data for the analysis. A five scale of measurements was used to measure the key indicators for construction materials and sustainable constructions.

The empirical support of the research is a natural development from the present state of the current literature as well as the existing opportunities and constraints that have formed the work process. In order to fulfill the aims, set at the problem statement, the empirically gathered data is needed to provide knowledge about the construction projects that have been completed and unfinished construction projects

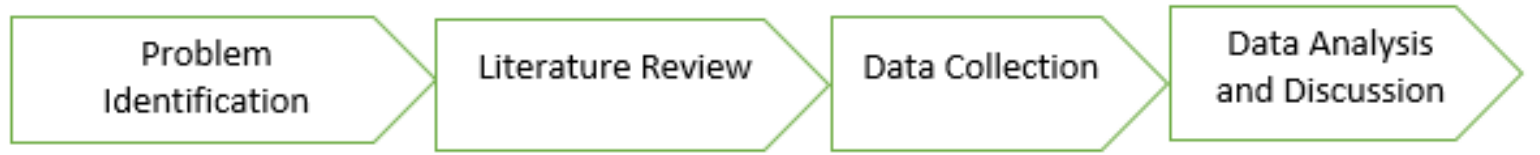

Figure 1: Flow Chart of for research design

The research design adopted in this study mainly focuses on the rules, techniques and procedures in line with the objectives of the study. Therefore, exploratory type and the mixed method approach was adopted for this study in the intention of dealing with a quantitative research approach with construction stakeholders was validated using qualitative interviews with concerned construction site supervisors.

The research data was obtained with the aid of a structured questionnaire survey (quantitative method), which was authenticated by conducting qualitative method shortly after the questionnaire survey. The quantitative method was used to collect data from construction stakeholders and contractors to identify the potential construction materials affecting sustainable buildings, the influence on the delivery of sustainable housings and the criteria to be considered in the selection of construction materials for optimum usage. The qualitative method was applied to evaluate the practice of sustainable building. Therefore, opinions were obtained through interviews and surveys.

Furthermore, exploratory type of study was employed in order to get a research questionnaire/surveys design to gain more perception into the research problem and to deliver solutions.

\subsection{Population of the Study}

For the purpose of this research, the issue to be addressed is the effect of construction materials on sustainable construction projects. With that in mind, the populations considered are construction stakeholders and contractors within the study area in construction industry.

The majority of the survey participants were construction professionals with all-embraced construction knowledge, skill and formal education. Site, contract, and project managers, site supervisors, designers, site engineers and quantity surveyors were the particularly nominated sample to denote the population for the purpose of this study.

The buildings under construction were selected from the list of registered buildings in construction using multistage random sampling. From the list of registered buildings, every fifth buildings under construction were chosen using random sampling till the required sample was reached.From the total 45 distributed questionnaires 40 questionnaires were received and the study conducted. 


\subsection{Sampling Technique}

To confirm the data obtained from the questionnaires; contractors, site supervisors and government experts were interviewed. These participants were selected for interviews using the suitability sampling method. Participants interviewed had adequate experience in construction, with adequate years of experience and responsibilities in the construction sector.

\subsection{Instrument for Data Collection}

Data was collected using open-ended and close-ended questionnaires in relation with the research objectives. Qualitative interviews were used to confirm the findings obtained through the quantitative research. Moreover, observations were also used as a technique that helped to get information that is left during formal interview sessions with informants just to grasp information about the unstated things during the interview and informal conversation periods.

\subsection{Techniques of Data Analysis}

Data were analyzed using descriptive analysis.All the statistical analyses and tests were done using application software "Microsoft excel". A Likert scale was used to measure the key indicators for sustainable construction materials and to determine the range of each respondent's Significant or Insignificant to statements by a ranking of 1-5 (1 for "Strongly Insignificant" (SI), 2 for "Insignificant" (IS), 3 for "Neutral" (N), 4 for "Significant" (S) and 5 for "Strongly Significant" (SS))

Finally, the Relative Important Index (RII) method was adopted for determining the rank for the "key factors Sustainable Construction Materials" by calculating the average of relative importance index of all factors in the group.

$R I I=\left(\frac{\sum(W)}{A * N}\right)$

Where: $\quad \mathrm{W}=$ the weight given to each factor by the respondents

$$
\begin{aligned}
& \mathrm{A}=\text { Strongly Significant }=5 \\
& \mathrm{~N}=\text { the total number of respondents. }
\end{aligned}
$$

\subsection{General Information}

\section{RESULTS AND DISCUSSION}

The objective of this study is to investigate and identify the influence of construction materials on sustainable constructionsprojects WolaitaSodo. To accomplish this goals a questionnaire was developed and distributed to be filled by the concerned body in the construction sectors in WolaitaSodo.

Table1: Study Results from the respondents for the Key Factors for Sustainable Construction Materials

\begin{tabular}{|c|l|c|c|c|c|c|c|c|c|c|c|c|c|}
\hline No. & Factors & $\mathbf{I}$ & & $\mathbf{2}$ & & $\mathbf{3}$ & & $\mathbf{4}$ & & $\mathbf{5}$ & & RII & Rank \\
\hline 1 & Escalation of material prices & 0 & $0 \%$ & 2 & $5 \%$ & 5 & $13 \%$ & 13 & $33 \%$ & 20 & $50 \%$ & 0.86 & 2 \\
\hline 2 & Material and equipment cost & 0 & $0 \%$ & 3 & $8 \%$ & 1 & $3 \%$ & 23 & $58 \%$ & 13 & $33 \%$ & 0.83 & 3 \\
\hline 3 & Labor cost & 2 & $5 \%$ & 3 & $8 \%$ & 6 & $15 \%$ & 19 & $48 \%$ & 10 & $25 \%$ & 0.76 & 9 \\
\hline 4 & Cost of variation orders & 0 & $0 \%$ & 4 & $10 \%$ & 3 & $8 \%$ & 17 & $43 \%$ & 16 & $40 \%$ & 0.83 & 3 \\
\hline 5 & Waste rate of materials & 1 & $3 \%$ & 15 & $38 \%$ & 15 & $38 \%$ & 8 & $20 \%$ & 1 & $3 \%$ & 0.57 & 12 \\
\hline 6 & Conformance to specification & 0 & $0 \%$ & 3 & $8 \%$ & 11 & $28 \%$ & 6 & $15 \%$ & 20 & $50 \%$ & 0.82 & 4 \\
\hline 7 & $\begin{array}{l}\text { Availability of personals with } \\
\text { high experience and qualification }\end{array}$ & 3 & $8 \%$ & 5 & $12 \%$ & 6 & $15 \%$ & 8 & $20.0 \%$ & 18 & $45.0 \%$ & 0.77 & 8 \\
\hline 8 & $\begin{array}{l}\text { Quality of equipment and raw } \\
\text { materials }\end{array}$ & 0 & $0 \%$ & 4 & $10 \%$ & 5 & $13 \%$ & 17 & $43 \%$ & 14 & $35 \%$ & 0.81 & 5 \\
\hline 9 & Wastes around the site & 0 & $0 \%$ & 4 & $10 \%$ & 6 & $15 \%$ & 14 & $35 \%$ & 16 & $40 \%$ & 0.81 & 5 \\
\hline 10 & Climate condition in the site & 2 & $5 \%$ & 4 & $10 \%$ & 3 & $8 \%$ & 14 & $35 \%$ & 17 & $43 \%$ & 0.80 & 6 \\
\hline 11 & Human toxicity & 2 & $5 \%$ & 6 & $15 \%$ & 5 & $13 \%$ & 7 & $18 \%$ & 20 & $50 \%$ & 0.79 & 7 \\
\hline 12 & Empowerment \& participation & 0 & $0 \%$ & 6 & $15 \%$ & 7 & $18 \%$ & 10 & $25 \%$ & 14 & $35 \%$ & 0.72 & 11 \\
\hline 13 & Adaptability & 0 & $0 \%$ & 6 & $15 \%$ & 5 & $13 \%$ & 13 & $33 \%$ & 16 & $40 \%$ & 0.80 & 6 \\
\hline
\end{tabular}




\begin{tabular}{|l|l|c|c|c|c|c|c|c|c|c|c|c|c|}
14 & Social value & 3 & $8 \%$ & 6 & $15 \%$ & 3 & $8 \%$ & 10 & $25 \%$ & 18 & $45 \%$ & 0.77 & 8 \\
\hline 15 & Life span & 2 & $5 \%$ & 3 & $8 \%$ & 8 & $20 \%$ & 15 & $38 \%$ & 12 & $30 \%$ & 0.76 & 9 \\
\hline 16 & Initial cost & 1 & $3 \%$ & 2 & $5 \%$ & 4 & $10 \%$ & 9 & $23 \%$ & 24 & $60 \%$ & 0.87 & 1 \\
\hline 17 & Job creation & 0 & $0 \%$ & 7 & $18 \%$ & 9 & $23 \%$ & 12 & $30 \%$ & 12 & $30 \%$ & 0.75 & 10 \\
\hline 18 & Tourism & 3 & $8 \%$ & 1 & $3 \%$ & 7 & $18 \%$ & 18 & $45 \%$ & 11 & $28 \%$ & 0.77 & 8 \\
\hline
\end{tabular}

Table below as per research study reveals the top 5 key factors for Sustainable Construction Materials, which we the researchers pay attentions according our perspective and from the respondent's point of understanding.

Table 2: The top 5 ranked key factors for Sustainable Construction Materials

\begin{tabular}{|c|l|c|c|c|c|c|c|c|c|c|c|c|c|}
\hline No. & Factors & $\mathbf{1}$ & & $\mathbf{2}$ & & $\mathbf{3}$ & & $\mathbf{4}$ & & $\mathbf{5}$ & & RII & Rank \\
\hline 1 & Initial cost & 1 & $3 \%$ & 2 & $5 \%$ & 4 & $10 \%$ & 9 & $23 \%$ & 24 & $60 \%$ & 0.87 & 1 \\
\hline 2 & Escalation of material prices & 0 & $0 \%$ & 2 & $5 \%$ & 5 & $13 \%$ & 13 & $33 \%$ & 20 & $50 \%$ & 0.86 & 2 \\
\hline 3 & Material and equipment cost & 0 & $0 \%$ & 3 & $8 \%$ & 1 & $3 \%$ & 23 & $58 \%$ & 13 & $33 \%$ & 0.83 & 3 \\
\hline 4 & Cost of variation orders & 0 & $0 \%$ & 4 & $10 \%$ & 3 & $8 \%$ & 17 & $43 \%$ & 16 & $40 \%$ & 0.83 & 3 \\
\hline 5 & Conformance to specification & 0 & $0 \%$ & 3 & $8 \%$ & 11 & $28 \%$ & 6 & $15 \%$ & 20 & $50 \%$ & 0.82 & 4 \\
\hline 6 & $\begin{array}{l}\text { Quality of equipment and raw } \\
\text { materials }\end{array}$ & 0 & $0 \%$ & 4 & $10 \%$ & 5 & $13 \%$ & 17 & $43 \%$ & 14 & $35 \%$ & 0.81 & 5 \\
\hline 7 & Wastes around the site & 0 & $0 \%$ & 4 & $10 \%$ & 6 & $15 \%$ & 14 & $35 \%$ & 16 & $40 \%$ & 0.81 & 5 \\
\hline
\end{tabular}

Top 5 Key Factors For Sustainable Construction

Materials

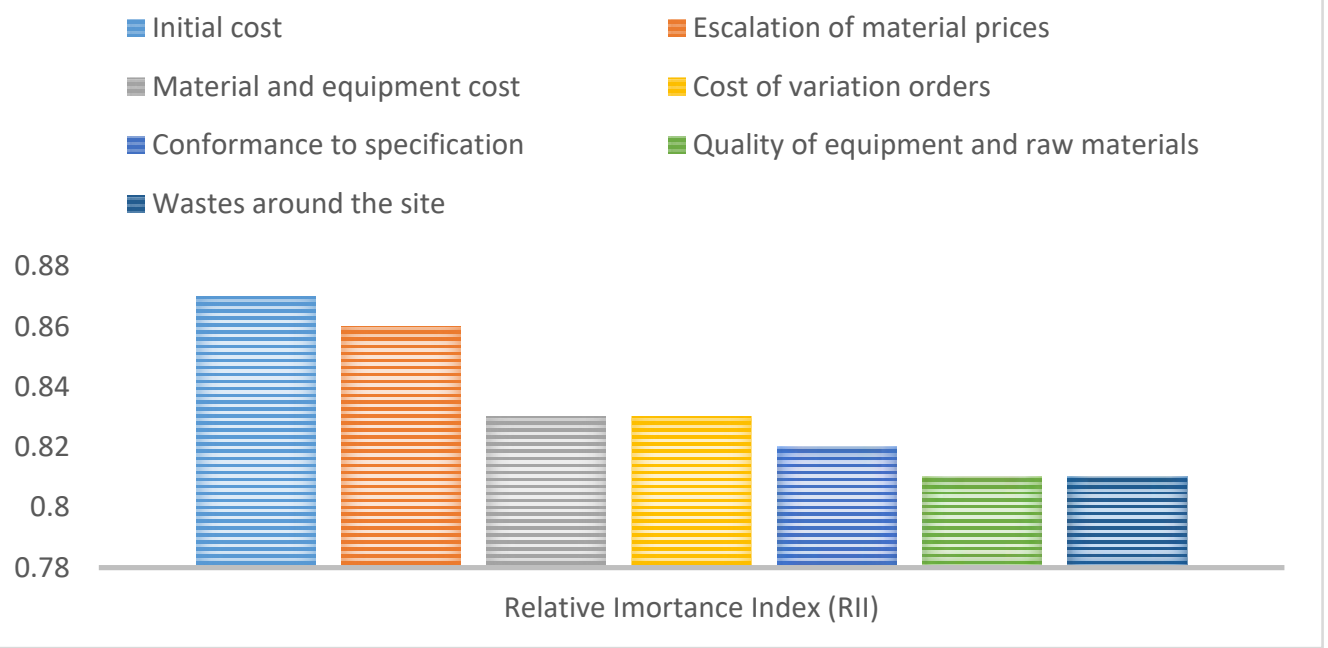

Figure2: Key Factors for Sustainable Construction Materials

The Table 2 and Char 1provides that the initial cost with relative important Index (RII $=0.87)$ takes the most top or the first place as that of the key factors for sustainable construction materials whereas escalation of material prices with the values of RII=0.86 comprises the second key factor. According to [9], substantial growth in the construction industry is subject to the price stability in building materials. However, in South Africa, this price increases at higher rates than expected.

Another very essential key factors which take the third place as that of the top important key factors are material and equipment cost, and cost of variation orders whose RII equals 0.833 . Client and project contractors have been facing serious challenges to maintain steady cost projection on construction projects [10]. The poor estimation of original project cost, poor design, variation and change orders, late site handovers, late delivery of design documents from the client or employee side are considered as the basic reasons for cost of variation orders in the buildingconstruction projects. 
Regarding quality as key indicator for sustainable construction, conformance to specification with the relative important index (RII $=0.82)$ takes the fourth place where as the quality of equipment and raw materials, and wastes around the site withequal relative importance index $(\mathrm{RII}=0.81)$ takes the fifth place as key indicators.

\section{CONCLUSTIONS}

Sustainability is essential to the environment and living in the domain of building, and must be a key watchword in this time. The practice of construction from conventional approaches are growing towards a sustainable progress. The main goal of this research work is to study and identify the influence of construction materials on sustainable construction projects. It was concluded that most of the concerned party in study area are familiar with the concept of sustainable construction. This research work also conclude that, all the 18 key factors/elements mentioned in Table 1 above are the emphasis of the respondents and study.

Therefore, by identifying the most important i.e. top five (initial cost, escalation of material prices, material and equipment cost, cost of variation orders, conformance to specification, quality of equipment and raw materials, and wastes around the site)of the key factorsof sustainable building materials and comparing them with the relevant details of the previous research, the research team reached to the right deductions as the listed out key elements are results of our research work.

\section{REFERENCES}

[1] Franzoni E, "Materials selection for green buildings: which tools for engineers and architects.," Procedia Engineering, vol. 21, pp. 883-890, 2011.

[2] Yiming Song and Hong Zhang, "sustainability of building materials," material science and Engineering, vol. 452, no. $022169,2018$.

[3] Ofori G, "Singapore's construction: moving toward a knowledge-based industry.," Building Research \& Information., 2002.

[4] Asif M, Muneer T and Kelley R , "Life cycle assessment: a case study of a dwelling home in Scotland.," 2005.

[5] Huberman N and Pearlmutter D, A life-cycle energy analysis of building materials in the Negev desert., 2008

[6] Bribian I.Z, Capilla A.V and Uson A.A, "Life cycle assessment of building materials: a comparative analysis of energy and environmental impacts and evaluation of the eco-efficiency improvement potential," Building and Environment, , vol. 46, p. 1133-1140, 2011.

[7] B. B, The ecology of building materials. Routledge, 2009.

[8] Abeysundara Y, Babel S and Gheewala S, "A matrix in life cycle perspective for selecting sustainable materials for buildings in Sri Lanka," Building and Environment, vol. 44, pp. 997-1004, 2009.

[9] Windapo, A and cattell, k, " Examine the Trends in Building Material Prices: Build Environment Stakeholders' Perspectives. In Proceedings of the Joint CIB International Symposium of W055, W065 and W089, W118, TG46, TG81 and TG84.," in International Conference on Construction managment Research, Montrel,QC,Canada, 2012

[10] Akanni, P.O, Oke,, A.E and Omotilewa, O.J., Implications of Rising Cost of Building Materials in Lagos State Nigeria. 